\title{
THE SEQUELAE AND SHORT-TERM PROGNOSIS OF ATTEMPTED SUICIDE

\author{
THE RESULTS OF A ONE-YEAR FOLLOW-UP OF 200 CASES
}

BY

\author{
I. R. C. BATCHELOR and MARGARET B. NAPIER \\ From the Royal Edinburgh Hospital for Nervous and Mental Disorders and the Department \\ of Psychiatry, University of Edinburgh
}

Dahlgren (1945) in Sweden, and Stengel and his associates (Stengel, 1952) in London, have previously reported systematic follow-up studies of cases of attempted suicide. Dahlgren studied 230 individuals, of whom 14 committed suicide within four years (15 were untraced), Stengel 138, of whom one committed and 17 attempted suicide within five years (11 were untraced). No attempt will be made here to summarize the other detailed findings of these investigations. The importance of such studies for the clinical assessment of suicidal attempts and for the validation of methods of their management needs no emphasis.

The present investigation is the second of its kind to be reported in this country, and has been made by those who originally investigated the suicidal attempts. This latter circumstance has enabled us to trace 199 of the 200 individuals involved. The results of the first year's follow-up are now recorded, since for practical purposes the short-term prognosis is of greatest importance.

\section{The Case Sample and Method of Follow-up}

Two hundred consecutive cases of attempted suicide admitted to the observation ward of a general hospital in the years 1950-52 were personally investigated at the time of their suicidal attempts, and have been followed-up one year later. The large majority of all persons attempting to commit suicide in the city of Edinburgh are admitted to this hospital, and it is likely that the sample is as representative of an urban population as it is possible to obtain.

The sex, ages, and diagnoses of the cases are detailed in Table I.

The follow-up investigation has been conducted, except in those cases to be mentioned, either by personal re-examination of the patient, or by interviewing the nearest relative or other responsible
TABLE I

SEX, AGE, AND DIAGNOSIS OF CASES

\begin{tabular}{|c|c|c|c|c|c|c|c|}
\hline Age & Male & $\left|\begin{array}{c}\mathrm{Fe}- \\
\text { male }\end{array}\right|$ & Total & Diagnosis & Male & $\begin{array}{c}\mathrm{Fe}- \\
\text { male }\end{array}$ & Total \\
\hline $15-19$ & 4 & 2 & 6 & Depressive state & 41 & 71 & 112 \\
\hline $20-29$ & 22 & 26 & 48 & Psychopathic state & 25 & 17 & 42 \\
\hline $30-39$ & 17 & 21 & 38 & Epilepsy & 3 & 9 & 12 \\
\hline $40-49$ & 17 & 14 & 31 & Schizophrenic and & 7 & 4 & 11 \\
\hline $50-59$ & 16 & 21 & 37 & Organic reaction types & 2 & 3 & 5 \\
\hline $60-69$ & 10 & 15 & 25 & Mental defect & 5 & - & 5 \\
\hline $\begin{array}{l}70 \text { and } \\
\text { over }\end{array}$ & 6 & 9 & 15 & Others* & 9 & 4 & 13 \\
\hline Total & 92 & 108 & 200 & Total & 92 & 108 & 200 \\
\hline
\end{tabular}

*" Others" includes some individuals near psychopathic and some near normal.

and informed person. In six cases a psychiatric social worker in another part of the country made a home visit for us ; in two cases we got a written report from the individual's general practitioner; and in two further cases a written account from another reliable informant. Only one man could not be traced. His death has not been registered. All relevant hospital documents have been scanned.

\section{Period in the Observation Ward}

One hundred and six (53\%) of the group were detained in the general hospital for one week or less, $69(34.5 \%)$ were detained for one to two weeks, and $25(12.5 \%)$ were detained for more than two weeks. Of those detained over two weeks, threefifths were discharged home.

Six (three men, three women) died in the observation ward. Of these, three were admitted to hospital when suffering from advanced disease of the central nervous system; the other deaths were due to respiratory or cardiovascular disease. This early mortality rate of $3 \%$ compares with the $5.9 \%$ 
reported from Liverpool (Hopkins, 1937) and the $5 \%$ from London (Stengel, 1952).

\section{Disposals from the Observation Ward}

One hundred and ninety-four individuals were discharged from the observation ward. Their disposals are given in. Table II.

TABLE II

DISPOSALS FROM OBSERVATION WARD

\begin{tabular}{|c|c|c|c|c|c|}
\hline \multicolumn{3}{|l|}{ Disposal } & \multirow{2}{*}{$\begin{array}{c}\text { Male } \\
51\end{array}$} & \multirow{2}{*}{$\frac{\text { Female }}{63}$} & \multirow{2}{*}{$\begin{array}{l}\text { Total } \\
114\end{array}$} \\
\hline Discharged home & .. & .. & & & \\
\hline $\begin{array}{c}\text { Transferred to mental } \\
\text { Voluntary patient } \\
\text { Under certificate }\end{array}$ & $\begin{array}{c}\text { hospital } \\
\ldots \\
\ldots\end{array}$ & $\begin{array}{l}\text { as } \\
\because \\
\cdots\end{array}$ & $\begin{array}{r}21 \\
2\end{array}$ & $\begin{array}{r}27 \\
5\end{array}$ & $\left.\begin{array}{r}48 \\
7\end{array}\right\} 55$ \\
\hline $\begin{array}{c}\text { Transferred to neuros } \\
\text { nursing home.. }\end{array}$ & $\begin{array}{l}\text { clinic } \\
\ldots\end{array}$ & $\begin{array}{l}\text { or } \\
\cdots\end{array}$ & 13 & 9 & 22 \\
\hline Others* .. & .. & .. & 2 & 1 & 3 \\
\hline
\end{tabular}

* " Others" includes returned to Service unit, returned to prison, admitted to hospital for incurables.

These disposals may be contrasted with those of two comparable series investigated in this country (Table III).

TABLE III

DISPOSALS COMPARED WITH TWO OTHER SERIES

\begin{tabular}{|c|c|c|c|}
\hline Investigation & $\begin{array}{l}\text { Batchelor, } \\
\text { Edinburgh } \\
\text { (1950-52) }\end{array}$ & $\begin{array}{l}\text { Hopkins, } \\
\text { Liverpool } \\
\text { (1932-35) }\end{array}$ & $\begin{array}{c}\text { Stengel, } \\
\text { London } \\
(1946-47)\end{array}$ \\
\hline Total no. of cases & 200 & 656 & 138 \\
\hline Discharged home & $57 \%$ & $57 \cdot 3 \%$ & $19 \cdot 6 \%$ \\
\hline $\begin{array}{c}\text { Transferred } \\
\text { hospital }\end{array}$ to mental & $27 \cdot 5 \%$ & $10 \cdot 7 \%$ & $72 \cdot 5 \%$ \\
\hline $\begin{array}{c}\text { Of these, certified } \\
\text { insane }\end{array}$ & $12 \cdot 7 \%$ & $100 \%$ & $38 \%$ \\
\hline 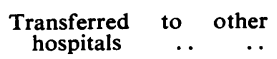 & $11 \cdot 5 \%$ & $10 \cdot 4 \%$ & $2 \cdot 9 \%$ \\
\hline Discharged to police ... & nil & $15 \cdot 7 \%$ & nil \\
\hline
\end{tabular}

In addition to the 55 individuals transferred directly from the observation ward, 10 others $(5 \%)$ were admitted to mental hospitals later in the first year. Of those discharged home from the observation ward, $61 \%$ were treated and investigated further as out-patients by the investigators.

\section{Deaths by Suicide}

Certainly three, probably four, individuals committed suicide in the year following their suicidal attempts ; three of the four had been admitted to hospital because the risk of a further attempt had been recognized.

Case 29.-This patient was a single woman, aged 25, suffering from a psychopathic state. Her abnormality had become apparent at an early age and was charac- terized by pathological lying, truancy, vindictiveness, petty crime, sexual promiscuity, and numerous changes of job. Periods spent in an approved school and at a neurosis clinic failed to modify her behaviour. Early on a New Year's Day at a party she swallowed barbiturate tablets which she was carrying in her pocket. Her suicidal intent seemed minimal. Apparently she had acted in pique, feeling that she was getting insufficient attention. Discharged home, she became estranged finally from her family, and frequented hotels where she deceived people into believing that she was a titled lady. Four months later, in a hotel in another town, she committed suicide by potassium cyanide poisoning.

Case 69.-A widow, aged 60, had developed an intractable involutional melancholia after the death of her husband in 1947. She had attempted suicide by coalgas poisoning in 1949 and was treated in a mental hospital for two months. In 1950 her only daughter became engaged to be married, and subsequently, on more than one occasion, the patient threatened to strike her daughter with an axe. In April, 1951, twice in one morning, she attempted to hang herself in her kitchen, and was twice cut down when nearly dead. Readmitted to a mental hospital under certificates, she called herself a criminal, at times blamed her daughter, and stated that she had been dominated by a fear of injuring her daughter. In November, 1951, two months after her discharge from hospital apparently recovered, she hanged herself in the waiting-room of a railway station. Her daughter broke off her engagement after her mother's death.

Case 143.-A widow, aged 57, had developed an involutional melancholia four months before, apparently precipitated by her own decision to turn out of her home a psychopathic daughter and her illegitimate child. She made a determined suicidal attempt by cut throat in a psychological setting of great guilt, fears of insanity, and identification with her dead husband. Admitted to a mental hospital, she was discharged after three months apparently well. Eight days later she committed suicide by cut throat.

Case 177.-An unemployed man, aged 64 , attempted suicide by barbiturate poisoning. Suffering from a manic-depressive psychosis, his depression had been characterized by insomnia (with great concern about it), feelings of increasing physical incapacity associated with chronic bronchitis, and loneliness (though married, he was living alone). Two years before he had been a patient in a mental hospital following a suicidal attempt by poisoning. Readmitted to a mental hospital as a voluntary patient, he was discharged recovered two months later. Seven months after the second suicidal attempt he was admitted semi-comatose to a general hospital and, without regaining consciousness, died after two days. The diagnosis recorded was "probable bronchopneumonia": the possibility of his having poisoned himself was not recognized. He had continued to live alone, since his wife had a resident occupation. 
It will be noted that two of the women were suffering from depressions in late middle-life : both were widows, and in each case the breakdown was related to an ambivalent relationship with a daughter, involving marked aggression and intense feelings of guilt. Despite apparently successful psychiatric treatment, they broke down again after re-exposure to the situation which had elicited their intense affects. The suicidal attempt of the psychopathic young woman might have been dismissed as a mere gesture. It is likely that ostracism by her longsuffering family was a potent factor in precipitating her suicide. Though suicide cannot be proven, the old man died in circumstances which suggest that his death was by suicide. Loneliness and estrangement from his wife were probably the major precipitating factors in his case.

\section{Later Deaths from Other Causes}

Of the 15 individuals who died from other causes after discharge from the observation ward, four died within three months, five within three to six months, and six within six to 12 months of their suicidal attempts.

A woman, aged 25, died of the pulmonary tuberculosis from which she had suffered for some years, and a woman, aged 39, died following a partial gastrectomy for peptic ulcer. The other 13 individuals were beyond middle-age : eight were aged 60 years or over. Causes of death in these 13 were : arteriosclerosis and senility, four ; coronary thrombosis, four; pneumonia, three; and cancer, two.

\section{Further Suicidal Attempts}

Seven individuals (two men, five women) made further suicidal attempts. Their histories can be sketched briefly.

Case 4.-A man, aged 65, unemployed, separated from his wife and living alone, had been depressed for some months. Due to appear in court for arrears of rent, he attempted suicide by gassing. His previous history revealed evidence of an inadequate psychopathic state, with passive homosexual trends. Discharged home, he attended as an out-patient and improved. Seven weeks later, when the psychiatrist went on holiday, he relapsed and again attempted suicide by cutting his wrists. He was then admitted to an old people's home and has kept well.

Case 23.-A woman suffering from an aggressive psychopathic state, married at the age of 40 a widower. Unable to adapt herself to married life she was frigid, felt tied down, and disliked intensely her three stepchildren. Two years later, after a quarrel with her husband, she made a determined suicidal attempt by aspirin poisoning. Admitted to a mental hospital as a voluntary patient, she continued to be aggressive and suicidal, and discharged herself within a month. Nine days later, following another quarrel with her husband, she again attempted suicide by coal-gas poisoning and was readmitted to a mental hospital.

Case 33.-A single man aged 31, suffering from epilepsy with gross emotional instability, attempted suicide by barbiturate poisoning after minor thwarting. He was unemployable, and there was a history of five previous suicidal attempts, leading to admissions to a mental hospital. He was discharged home. Five months later he attempted to hang himself, and was readmitted to a mental hospital under certificates : he stated that he had felt " fed-up " because of his headaches and inability to work.

Case 48. - An emotionally unstable, sexually promiscuous, and intellectually dull woman, aged 38 , who also suffered from epilepsy, impulsively attempted suicide by drowning after a tiff with a young man. She had twice previously been a patient in a mental hospital. On this occasion she was discharged home. Three weeks later she again attempted suicide, jumping from a secondfloor window: she stated that she had had a "dizzy turn ". There being no vacancy in a suitable institution, she was again returned home.

Case 71.-A married woman, aged 44 , suffering from epilepsy with personality disorder, attempted suicide by barbiturate poisoning two months after the death of one of her children. This child had been ill in bed with tonsillitis: while she was playing with him he died, and she said she might have smothered him in the bed-clothes. In the previous year she had made two suicidal attempts, the second leading to admission to a mental hospital. She was again admitted to a mental hospital as a voluntary patient. Eleven months later at home, when the Society for the Prevention of Cruelty to Children was investigating the possiblity of ill-treatment of her eldest son, she again attempted suicide by barbiturate poisoning. She was readmitted to a mental hospital.

Case 110.-A married woman, aged 36, epileptic and temperamentally grossly unstable, had made four previous suicidal attempts by jumping, barbiturate poisoning, and coal-gas poisoning : more than one of these attempts had been nearly fatal. When drunk she made a further suicidal attempt by coal-gas poisoning, after a quarrel during which she struck her husband. Admitted to a mental hospital under certificates, she remained there nine months. Six weeks after discharge she made a further suicidal attempt by barbiturate poisoning, and was readmitted to a mental hospital.

Case 148.-A married woman, aged 51, of hysterical personality, had first developed incapacitating nervous symptoms 10 years before. A chronic invalid reaction developed, with hypochondriasis and depressive moods. Overdoses of drugs were taken on several occasions. After her husband had been admitted to hospital seriously ill, she attempted suicide by barbiturate 
poisoning. Mental hospital treatment was advised but refused. Seven months later she made a further suicidal attempt by the same method. Again neither she nor her relatives would agree to psychiatric treatment.

It will be noted that all these individuals were of chronically unstable temperament: four were epileptic, two psychopathic, and one showed a hysterical personality disorder of severe degree. Three received mental hospital treatment, one refused treatment, and another could not be accommodated. The characteristics of this suicidal group and their repeated attempts at self-injury have been discussed more fully elsewhere (Batchelor, 1954).

\section{Assaults}

Several men were reported as having attacked their wives. A feeble-minded man, four months after his suicidal attempt, was committed to a State institution for seriously assaulting another man. A manic-depressive and dipsomaniac patient, who had refused hospital treatment after his suicidal attempt, came to hospital one month later saying that he must be restrained since he intended to kill his wife : he had bought a knife for the purpose. Though our information about assaultive behaviour is not complete, it appears that a similar percentage of individuals commit serious assaults as make further suicidal attempts.

\section{Social Reverberations of the Suicidal Attempts}

To record the social reverberations of a suicidal attempt is difficult, and to do so completely, probably impossible. We present here a summary of some of the information we obtained about the social aspects of these attempts.

It should be noted that the large majority of those who received in-patient psychiatric care, did so voluntarily : that is, they accepted that admission to hospital either was necessary to ease their suffering or offered some hope of deliverance from an impasse. On the other hand, their suicidal attempts had compelled the attention of others to the seriousness of their sickness, and had thus facilitated more effective treatment. One may note that this is comparable to what may happen in cases of physical illness ; when, for example, the sufferer from apparently trivial indigestion develops a gastric perforation which requires surgical operation. Or one may prefer (Stengel, 1952) to interpret the sequence as evidence that a suicidal attempt constitutes an appeal to society for effective help.

Most of the group were not admitted to hospital. Amongst these, a small number, about $5 \%$ of the total group of 200, improved their social positions as a result of their suicidal attempts. If their acts were attempts to manipulate the environment in a direction favourable to themselves, they seemed to achieve that purpose. We include those cases in which a spouse or lover was, when disaffected, persuaded to give the potential suicide another trial instead of leaving him; or was rendered more considerate ; or when unwanted was got rid of ; and those cases whose situation was improved by society undertaking their further care in a hostel or Eventide Home. A similar small proportion of the group worsened their positions. Contrary to their wishes their marriage was disrupted, a lover lost, or their family decided finally to reject them.

In about $15 \%$ of all the cases the suicidal attempt proved emotionally disturbing for several or many months to one or more of the near relatives. As would be expected, spouses, offspring, and mothers were most often affected. In at least three cases relatives required psychiatric treatment for severe symptoms. One woman herself attempted suicide seven months after her sister's suicidal attempt, and their acts were directly related.

We obtained information only about the grosser reactions of the relatives concerned, and we know nothing of what had been for the meantime repressed successfully, but which may later have a traumatic influence. However, we certainly found less severe disturbance than we had expected. We were impressed by how frequently the suicidal attempt had made no great commotion in the family group : the individual recovered from his illness and resumed easily a successful course in life ; or the lamentable interchanges of a cat-and-dog existence were taken up again where they had been left off. In several cases a year later there was an improved situation to report-which had not been an outcome of the suicidal attempt-a happy marriage made, a better job found, or a new house.

Of those initially admitted to a mental hospital, $33 \%$ were discharged home recovered or relieved in the first three months, and a further $31 \%$ in the next three months. A further six individuals were discharged from a mental hospital between six months and one year after admission.

Table IV indicates that at the end of one year approximately four-fifths of those who were not in hospital were employed, and this gives some measure of the degree of readjustment which they had reached. The presence of a considerable psychopathic group, more or less stabilized and more or less symptom-free, rendered impossible a neat separation of these individuals into the two categories of " nervously ill " and " fit".

The diagnoses of the 17 individuals who remained 
TABLE IV

POSITION AT END OF ONE YEAR

\begin{tabular}{|c|c|c|c|c|c|c|}
\hline & & & & Male & Female & Total \\
\hline Total group & . & . & . & 92 & 108 & 200 \\
\hline Dead .. & . & . & . & 12 & 9 & $21(10 \cdot 5 \%)$ \\
\hline \multicolumn{7}{|c|}{ In mental hospital- } \\
\hline Out of hospit & & . & . & 66 & 85 & $151(75.5 \%)$ \\
\hline Employed & .. & .. & .. & 51 & 67 & $118(59 \%)$ \\
\hline Not known & $\ldots$ & .. & .. & 1 & - & 1 \\
\hline
\end{tabular}

in the mental hospitals to which they had been transferred from the observation ward were : depressive psychoses, nine; schizophrenia and paranoid states, six; general paralysis, one ; psychopathic state, one.

\section{Discussion}

Before discussing the propriety of the disposals of these cases, we must emphasize that while the individual was still a patient in the observation ward his state was in every case thoroughly assessed from the psychiatric, physical, and social aspects. A decision about further management was made therefore on the basis of considerable knowledge. It might well be unjustifiable to dispose similarly of a group of attempted suicides who had been more superficially examined.

The majority were discharged home after a period of less than a fortnight in the general hospital. Less than one-third were admitted to a mental hospital, and, though many were technically certifiable, only seven were certified as of unsound mind. Was this rather free policy justified by its results? We believe that our follow-up study has demonstrated that it was.

Only one individual (Case 29) committed suicide, whose fatal action was quite unexpected by us, and in retrospect we do not feel that any undue risk was taken in this case. She, and all seven who later unsuccessfully attempted suicide, belonged to the chronically temperamentally unstable group, for whom we have at present no effective treatment or suitable provision : such people repeatedly hazard their lives and we cannot permanently safeguard them. The two, probably three, others who took their lives, did so after they had received mental hospital treatment.

Amongst the attempted suicides mental hospital care and treatment are required most often for those suffering from depressive, schizophrenic, and paranoid psychoses. It is more often required for those past middle-age than for younger individuals. It is necessary for the majority of those aged 60 or over, but it is not necessary for the majority of those of all ages. A policy of sending most attempted suicides to mental hospitals is in our view over-cautious, and, especially at a time of acute shortage of accommodation, wasteful. (That it was found necessary to send $73 \%$ of the group investigated by Stengel to mental hospitals underlines his statement that his group was atypical.)

The results of this follow-up emphasize once again the serious suicidal risk which accompanies the depressions of later middle-life and the senium, and which persists far into convalescence. Our experience further suggests that when a depressive psychosis has been precipitated by breakdown in a relationship characterized by intense possessive love, and when the aggression consequent upon this severe disappointment has resulted in an attack upon or other overt hostility towards that relative, the ensuing guilt tends to be of such proportions that only death by suicide can expiate it. We hope that later follow-up studies of our cases may enable us to identify other situations, internal conflicts, and reaction-types especially fraught with the danger of suicide.

Stengel (1952) has written: "There is a social element in the pattern of most suicidal attempts. Once we look for that element we can find it without difficulty in most cases." He stresses the "appeal character" of suicidal acts, considering them to be directed Janus-faced both towards a renewal of human relationships and towards death. This is a valuable formulation. Our data, where they do not confirm his findings and concepts, tend rather to qualify than to contradict them.

Stengel states that the suicidal attempt usually results in some modification of the individual's social situation: "For many patients the suicidal attempt initiates a new era in their relationship to their environment ..." While this is undoubtedly true in certain instances, we found that it was not true of the majority of our cases, and was true perhaps only of a small minority. He suggests that the number of those who, having first attempted suicide, later kill themselves, will depend largely on the reaction of their human environment to the suicidal attempt. Here our findings support, though they are insufficient to prove, his hypothesis. In three (Cases 29, 69, 177) of the four cases of death by suicide, estrangement in personal relationships had contributed largely to precipitate breakdown : the suicidal attempt had not healed this alienation, but in one case at least (Case 29) had aggravated it. Furthermore, apparent symptomatic 
recovery in a sheltered environment had not been accompanied by the necessary social readjustment, either of the individual or of his group. These facts remind us how necessary it is in cases of nervous and mental illness to understand and to treat the patient in his social context. By doing so thoroughly, we may prevent some suicides.

The appeal element is present most frequently and prominently in the suicidal attempts of certain temperamentally unstable individuals chronically in conflict with their society. It is doubtful if it is an element in all suicidal attempts. The melancholic, for example, his distress centred entirely on himself, may ignore human contacts and attempt suicide because he believes there is no other way of relief, or because his guilt seems to demand capital punishment. An over-emphasis upon the " appeal character" of suicidal attempts might lead to an under-emphasis of their danger. Further data must be obtained before we can depict definitively their characteristics, and Stengel utters a timely warning against undue optimism in prognosis. Obviously also one cannot reach a satisfactory understanding of a particular suicidal attempt by means of still rather tentative views of the general significance of these acts. The precise motives must be elicited in each case before appropriate treatment can be instituted.

\section{Summary}

Two hundred consecutive cases of attempted suicide admitted to a general hospital and personally investigated from psychiatric and social aspects have been followed up a year later. One hundred and ninety-nine were traced.
Fifty-seven per cent. were discharged home from the general hospital, and less than one-third required mental hospital treatment. This rather free policy in disposals seemed justified by its results.

One year later, $13.5 \%$ of the group were in mental hospitals, $76 \%$ were at home, and $59 \%$ were employed.

The over-all mortality in the first year, which involved mainly those past middle-age, was $10 \cdot 5 \%$. Three, probably four, individuals $(2 \%)$ committed suicide.

Seven other individuals (3.5\%) made further suicidal attempts. Several men committed assaults.

The detailed findings indicate that those who show persistently psychopathic behaviour are apt to repeat their suicidal attempts; that depressive psychoses carry their serious suicidal risk late into convalescence; and that social factors may play a considerable role in aggravating a suicidal trend to a fatal outcome.

The social reverberations of the suicidal attempts of the group, upon themselves and their families, are reported; and the "appeal character" of suicidal attempts is more briefly discussed.

We are grateful to Professor Sir David K. Henderson for his advice, and to Dr. J. K. Slater for permission to study these cases in his wards at the Edinburgh Royal Infirmary.

\section{REFERENCES}

Batchelor, I. R. C. (1954). Brit. J. med. Psychol., 27, 158 Dahlgren, K. G. (1945). On Suicide and Attempted Suicide. Lindstedts, Lund.

Hopkins, F. (1937). J. ment. Sci., 83, 71.

Stengel, E. (1952). Proc. roy. Soc. Med., 45, 613. 